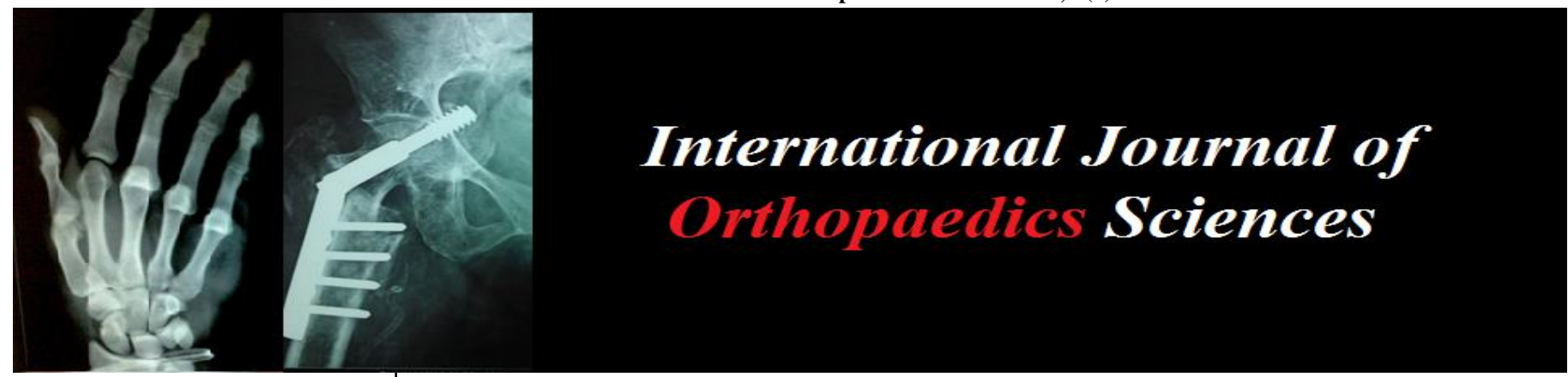

ISSN: $2395-1958$

IJOS 2019; 5(3): 666-669

(C) 2019 IJOS

www.orthopaper.com

Received: 18-05-2019

Accepted: 24-06-2019

Chatupon Chotigavanichaya Department of Orthopedic Surgery, Faculty of Medicine Siriraj Hospital, Mahidol University, Bangkok, Thailand

Jidapa Wongchareonwatana Department of Orthopedic Surgery, Faculty of Medicine Siriraj Hospital, Mahidol

University, Bangkok, Thailand

Charikdhamma Saelim Department of Orthopedic Surgery, Faculty of Medicine Siriraj Hospital, Mahidol

University, Bangkok, Thailand

Thanase Ariyawatkul Department of Orthopedic Surgery, Faculty of Medicine Siriraj Hospital, Mahidol University, Bangkok, Thailand

Kamolporn Kaewpornsawan Department of Orthopedic Surgery, Faculty of Medicine Siriraj Hospital, Mahidol University, Bangkok, Thailand

\section{Perajit Eamsobhana}

Department of Orthopedic Surgery, Faculty of Medicine Siriraj Hospital, Mahidol University, Bangkok, Thailand

Correspondence

Perajit Eamsobhana Department of Orthopedic Surgery, Faculty of Medicine Siriraj Hospital, Mahidol University, Bangkok, Thailand

\section{Comparison of ponseti method versus surgical treatment in congenital idiopathic clubfoot: A 5-year follow up study}

\author{
Chatupon Chotigavanichaya, Jidapa Wongchareonwatana, Charikdhamma \\ Saelim, Thanase Ariyawatkul, Kamolporn Kaewpornsawan and Perajit \\ Eamsobhana
}

DOI: https://doi.org/10.22271/ortho.2019.v5.i31.1610

Abstract

Background: Congenital idiopathic clubfoot is a complex congenital deformity. The goal of treatment is to achieve pain-free plantigrade feet with good mobility and without deformity. Prior treatment for congenital idiopathic clubfoot included manipulation, serial casting, and major soft tissue release surgically by any of the following techniques: modified posteromedial release, complete subtalar release and posterior release. The objective of this study was to compare the functional outcome between Ponseti method and major surgical treatment.

Materials and Methods: This prospective cohort study was conducted in congenital idiopathic clubfoot patients who underwent primary treatment by either Ponseti serial casting or major surgical soft tissue release between 2000 to 2012. Outcome measurements included the Functional Rating System of Laaveg and Ponseti, the talocalcaneal angle (TCA) in antero-posterior (AP) and lateral view radiographs.

Results: Nineteen children ( 28 feet) were treated with Ponseti method and 19 children (30 feet) were treated with major surgery. The minimum follow up was 5.07 years (mean $5.94 \pm 1.01$ years in the Ponseti group and $8.73 \pm 2.78$ years in the surgical treatment group). In the last follow up, there was statically significant difference of the mean Functional Rating score between the Ponseti group and major surgery group. (95.35 \pm 2.31 and $89.76 \pm 4.97, p<0.001)$. There was statically significant difference of the satisfaction score between the Ponseti group and major surgery group (20 and 18.27 $\pm 2.01, p<0.001)$. The passive motion score was statically significant better in Ponseti group $(5.79 \pm 1.37$ and $4.57 \pm 1.45$, $\mathrm{p}=0.003)$. The mean TCA in AP and lateral views were within normal range in both groups with statically significant better in Ponseti group $(24.89 \pm 4.83$ and $21.63 \pm 4.62, p=0.009$ and $23.46 \pm 4.88$ and 21.13 $\pm 7.96, \mathrm{p}=0.013$ ).

Conclusion: Ponseti method is effective and satisfactory treatment for congenital idiopathic clubfoot and should be considered as initial treatment for congenital idiopathic clubfoot. Major surgery should be reserved for deformity that cannot be completely corrected.

Keywords: Ponseti method, congenital idiopathic clubfoot, talocalcaneal angle

\section{Introduction}

Congenital idiopathic clubfoot is a complex congenital deformity affecting the foot which characterized by equinus, hindfoot varus, midfoot cavus and forefoot adductus. The incidence is approximately $1-6$ cases per 1,000 live births ${ }^{[1-4]}$. It is three times more common in males. The goal of treatment is to achieve pain-free plantigrade feet with good mobility and without deformity ${ }^{[5,6]}$.

Majority of the patients previously required surgical correction. During the last two decades, the Ponseti method seems to have become the standard treatment of congenital idiopathic clubfoot ${ }^{[6-11]}$

Prior to 2006 the treatment for congenital idiopathic clubfoot was manipulation, serial casting, and major surgical soft tissue release including modified posteromedial release, completed subtalar release and posterior release. Ponseti method was officially introduced at author's institute hospital since 2006. 
The objective of this study was to compare the Ponseti method to the previous major surgical treatment including functional outcome, radiographic outcome, recurrence rate and complications.

\section{Materials and methods}

This prospective cohort study was conducted in congenital idiopathic clubfoot patients who underwent primary treatment by either Ponseti serial casting or major soft tissue release between 2000 to 2012 at Department of Orthopaedic Surgery, in author's institute hospital.

Patients in the major soft tissue surgical treatment group were treated with manipulation, serial casting by Imhauser technique $^{[12]}$ then underwent one or more of the following procedures such as modified posteromedial release, complete subtalar release and posterior release. Patient in the Ponseti group was treated as regimen described by Ponseti. All patients of both groups were followed up for at least five years.

Exclusion criteria included non-congenital idiopathic clubfoot, such as postural clubfoot, neuropathic or another syndromic clubfoot, and incomplete medical data.

The outcome measures used to assess foot function was the Functional Rating System for clubfoot (FRS) of Laagveg and Ponseti ${ }^{[6]}$. This questionnaire consists of three questions regarding the patients' satisfaction (maximum 20 points), function (maximum 20 points) and pain (maximum 30 points). In addition, the examiner evaluates the foot based on the position of heel while standing (maximum 10 points), the flexibility of the foot in dorsiflexion of the ankle, varusvalgus motion of the subtalar joint, and inversion-eversion (maximum 10 points). Finally gait pattern is evaluated (maximum 10 points). The total maximum score is 100 points.

Radiographs of the feet were taken in standard anteroposterior and lateral weight bearing views when the patients were at least five years follow up examination. Anteroposterior and lateral talocalcaneal angle were measured.

The recurrence rate and complications after treatment were evaluated.

For both groups, descriptive statistics were calculated for the FRS total scores and all categories, radiographic parameters, recurrence rate, and complications. The comparison of the FRS total scores and its categories, radiographic parameters, and complications between the two groups was analyzed by nonparametric tests (Mann-Whitney U-tests)

\section{Results}

Total of 58 feet in 38 patients (18 males and 20 females), Twenty-eight (19 patients) were in the Ponseti group and 30 feet (19 patients) were in the surgical treatment group. The minimum follow up time was 5.07 years (mean 5.94 \pm 1.01 years in the Ponseti group and $8.73 \pm 2.78$ years in the surgical treatment group). The mean age at the start of the treatment was $6.18 \pm 5.08$ weeks in the Ponseti group, and $7.77 \pm 5.81$ weeks in the surgical treatment group (Table. 1).

When the foot function was evaluated at the age of at least 5 years, patients in the Ponseti group scored higher in the FRS total score $(p<0.001)$ (Table. 2). The FRS category All feet had a plantigrade position when standing and had good function in both groups $(p=1.00$ and $p=0.14$ respectively). The FRS category for gait was comparable in both groups. For passive motion category of the FRS, passive maximal dorsiflexion, varus-valgus, and inversion-eversion mobility scores were higher in the Ponseti group $(p=0.003)$. None of the patients in the Ponseti group experienced foot pain. Eight feet (5 patients) in the surgical treatment group reported occasionally mild foot pain during strenuous activities $(\mathrm{p}=0.004)$.

For satisfaction category describing the level of caregiver contentment scores, in the Ponseti group were higher than the surgical treatment group $(p<0.001)$. For gait category, all patients in both groups walked normally. However, patients in the Ponseti group can perform toe-walk and heel walk better than surgical treatment group $(p<0.001)$.

For radiographic outcome, the mean AP talocalcaneal angles in both groups were in normal range but significant higher in the Ponseti group when compared to surgical treatment group (24.89 \pm 4.83 and $21.63 \pm 4.62$ degree respectively, $\mathrm{p}=0.009)$. The lateral talocalcaneal angle in both groups were slightly less than the normal range, but significant higher in the Ponseti group $(23.46 \pm 4.88$ and $21.13 \pm 7.96$ degree respectively, $\mathrm{p}=0.013)^{[13]}$ (Table. 3 ).

The recurrence rate in surgical treatment group was higher than the Ponseti group but no statistically significant $(\mathrm{p}=0.64)$.

Complications associated with both the Ponseti method and surgical treatment groups are shown in Table 4.

\section{Discussion}

The Ponseti method is now used worldwide to treat congenital idiopathic clubfoot. Ponseti casting can also be used to treat syndromic or neurogenic clubfoot, but treatment outcomes are inferior to outcomes observed in congenital idiopathic clubfoot patients ${ }^{[14-17]}$. Prior to 2006, all congenital idiopathic clubfoot cases treated at our institute were treated with modified posteromedial release, complete subtalar release, or posterior release at patient age of 9 to 12 months. It was common for surgery to be postponed until a more suitable time and/or the patient achieved an appropriate weight ${ }^{[18]}$. Some patients were initially treated by serial casting until foot physiology and weight gain were sufficiently adequate for performing major surgery. At our institute, the Ponseti method was adopted as the treatment of choice for this condition in $2006^{[18]}$.

When evaluating foot function at 5 years after treatment, we observed differences in several categories of the FRS of Laaveg and Ponseti. The parent/patient reported outcome was significantly better after the Ponseti treatment. In their study, the average score was 87.5 compared to $95.35 \pm 2.31$ points in our Ponseti group.

The category satisfaction describing the level of care giver contentment suggested parents of patients in the Ponseti group were very satisfied with the middle-term outcome, where as parents of patients in surgical treatment group were satisfied or very satisfied. Laaveg and Ponseti evaluated 104 clubfeet and reported $72 \%$ very satisfied patients, $19 \%$ satisfied, and $4 \%$ not satisfied with the long term outcome ${ }^{[6]}$. Because the FRS scores are described to correlate with age, the high score in our study must be interprete with caution. However, the less invasive character of the Ponseti method without need for wound management and the shorter hospital stay seem to contribute parental satisfaction. The passive mobility category in the FRS revealed better mobility of the feet in dorsiflexion, varus-valgus, and inversion-eversion for the Ponseti group with scores similar to those reported by Laaveg and Ponseti ${ }^{6,}$ 11]. For gait category, all patients in both groups walked normally, but patients in the Ponseti group could perform toewalk and heel walk better than surgical treatment group.

The AP and lateral talocalcaneal angles are the most widely 
used parameters and reflected the anatomic relationship between the talus and the calcaneus. A higher AP talocalcaneal angle was associated with a better functional outcome. This was concurred with several previous studies ${ }^{[19}$, 20], although many authors have found strong correlation between the functional rating and lateral talocalcaneal angle $[19,21,22]$. In our study, the mean AP and lateral talocalcaneal angles in the Ponseti group were significantly higher than the surgical group.

The complications associated with the treatment were $17.9 \%$ in the Ponseti group and $33.3 \%$ in surgical treatment group. In the Ponseti group, all of the complications were cast loosening but in the surgical treatment group, the most common complications were cast loosening and cast associated pressure sore. Some studies reported cast complication rates of $5-20 \%$, which is comparable to the $17.9 \%$ in the Ponseti group in our study ${ }^{[18]}$.

In surgical treatment group, the surgical related wound infection was found in 2 feet $(6.7 \%)$. All of which were treated with wound dressing and oral antibiotics. Some studies reported the surgical related wound infection 5.94$12.8 \%$, which is comparable to the $6.7 \%$ in our study ${ }^{[18]}$. Other complications observed in our study were minor casts complications during manipulation before surgery and after surgery for maintaining the position of the foot.

Regarding second operation for recurrent deformity, some studies reported secondary procedure $2-30.43 \%{ }^{[7,18,23]}$. The present study found that $17.9 \%$ in the Ponseti group and $26.7 \%$ in surgical treatment group required secondary procedure after treatment, which is comparable to our study.

Table 1: Demographic data

\begin{tabular}{|c|c|c|c|}
\hline & Ponseti $(\mathrm{n}=28)$ & Major surgery $(\mathrm{n}=\mathbf{3 0})$ & p-value \\
\hline Number of patients & 19 & 19 & \\
\hline \multicolumn{4}{|l|}{ Gender } \\
\hline Male & $9(47 \%)$ & $9(47 \%)$ & \\
\hline Female & $10(53 \%)$ & $10(53 \%)$ & \\
\hline Number of feet & 28 & 30 & \\
\hline \multicolumn{4}{|l|}{ Side } \\
\hline Right & $11(39.3 \%)$ & $14(46.7 \%)$ & \\
\hline Left & $17(60.7 \%)$ & $16(53.3 \%)$ & \\
\hline Bilateral & 9 & 11 & \\
\hline \multicolumn{4}{|l|}{ Type of surgery } \\
\hline PMR & - & $22(73.3 \%)$ & \\
\hline TAL + posterior release & & $8(26.7 \%)$ & \\
\hline Age at start of cast treatment (weeks) & $6.18 \pm 5.08(1-24)$ & $7.77 \pm 5.81(1-20)$ & 0.57 \\
\hline Number of casts & $5.68 \pm 1.7(2-12)$ & $6.4 \pm 1.32(4-9)$ & 0.85 \\
\hline Age at percutaneous tenotomy (weeks) & $33.79 \pm 30.79(11-142)$ & & \\
\hline Age at major surgery (weeks) & & $59.95 \pm 72.61(15.57-307.14)$ & \\
\hline Follow up time & $5.94 \pm 1.01(5.07-8.35)$ & $8.73 \pm 2.78(5.07-13.95)$ & \\
\hline
\end{tabular}

Table 2: Laaveg and Ponseti's Functional Rating System for clubfoot

\begin{tabular}{|c|c|c|c|c|}
\hline Category & $\begin{array}{c}\text { Surgery group n = 30 feet } \\
\text { (mean score) }\end{array}$ & $\begin{array}{c}\text { Ponseti group n= 28 feet } \\
\text { (mean score) }\end{array}$ & $\begin{array}{c}\text { Mean difference } \\
\text { (95\% CI) }\end{array}$ & $\begin{array}{c}\text { p- } \\
\text { value }\end{array}$ \\
\hline \multicolumn{7}{|c|}{ Parent/patient reported outcome } \\
\hline Satisfaction (max. 20 pts.) & $18.27 \pm 2.01(16-20)$ & 20 & $1.73(0.97-2.49)$ & $<0.001$ \\
\hline Function (max. 20 pts.) & 20 & $19.71 \pm 1.04(16-20)$ & $0.28(-0.66-0.98)$ & 0.14 \\
\hline Pain (max. 30 pts.) & $28.4 \pm 2.69(24-30)$ & 30 & $1.6(0.57-2.62)$ & 0.004 \\
\hline \multicolumn{7}{|c|}{ Physical examination/evaluation } & 10 & 0 & $<0.999$ \\
\hline Heel position (max 10 pts.) & 10 & $5.79 \pm 1.37(3-8)$ & $1.21(0.47-1.96)$ & 0.003 \\
\hline Passive motion (max. 10 pts.) & $4.57 \pm 1.45(2-7)$ & $9.86 \pm 0.52(8-10)$ & $1.32(0.8-1.84)$ & $<0.001$ \\
\hline Gait (max. 10 pts.) & $8.53 \pm 1.27(6-10)$ & $95.35 \pm 2.31(89-98)$ & $5.59(3.52-7.65)$ & $<0.001$ \\
\hline Total score (max. 100 pts.) & $89.76 \pm 4.97(78-97)$ & &
\end{tabular}

Table 3: Radiographic outcome

\begin{tabular}{|c|c|c|c|c|}
\hline & $\begin{array}{c}\text { Surgery group } n=30 \text { feet } \\
\text { (mean score) }\end{array}$ & $\begin{array}{c}\text { Ponseti group } n=28 \text { feet } \\
\text { (mean score) }\end{array}$ & $\begin{array}{l}\text { Mean difference } \\
(95 \% \mathrm{CI})\end{array}$ & p-value \\
\hline AP talocalcaneal angle & $21.63 \pm 4.62$ & $24.89 \pm 4.83$ & $3.26(0.75-5.76)$ & 0.009 \\
\hline Lateral talocalcaneal angle & $21.13 \pm 7.96$ & $23.46 \pm 4.88$ & $2.33(-1.17-5.83)$ & 0.013 \\
\hline
\end{tabular}

Table 4: Complication associated with treatment

\begin{tabular}{|c|c|c|c|}
\hline Complication & Surgery group n = 30 feet (\%) & Ponseti group n= 28 feet (\%) & p-value \\
\hline Cast complication & & & \\
\hline Cast loosening & $4(13.3 \%)$ & $5(17.9 \%)$ & \\
\hline Cast-associated pressure sore & $4(13.3 \%)$ & & \\
\hline Surgical complication & $2(6.7 \%)$ & & \\
\hline Infection & $8(26.7 \%)$ & & 0.64 \\
\hline Recurrence & & $5(17.9 \%)$ & \\
\hline
\end{tabular}




\section{Conclusion}

Ponseti method is a safe, effective and satisfactory treatment for congenital idiopathic clubfoot and should be considered asinitial treatment for congenital idiopathic clubfoot. Open surgery should be reserved for deformity that cannot be completely corrected.

\section{Acknowledgement}

The authors would also like to Miss Suchitphon Chanchoo, research officer for formatting manuscript.

\section{References}

1. Bellyei A, Czeizel A. A higher incidence of congenital structural talipes equinovarus in gypsies. Hum Hered. 1983; 33(1):58-59.

2. Bensahel H, Guillaume A, Czukonyi Z, Desgrippes Y. Results of physical therapy for idiopathic clubfoot: A long-term follow-up study. J Pediatr Orthop. 1990; 10(2):189-192.

3. Boo NY, Ong LC. Congenital talipes in Malaysian neonates: incidence, pattern and associated factors. Singapore Med J. 1990; 31(6):539-542.

4. Chotigavanichaya C, Leurmsumran P, Eamsobhana P, Sanpakit S, Kaewpornsawan K. The incidence of common orthopaedic problems in newborn at Siriraj Hospital. J Med Assoc Thai. 2012; 95(9):S54-61.

5. Ippolito E, Ponseti IV. Congenital club foot in the human fetus. A histological study. J Bone Joint Surg Am. 1980; 62(1):8-22.

6. Laaveg SJ, Ponseti IV. Long-term results of treatment of congenital club foot. J Bone Joint Surg Am. 1980; 62(1):23-31.

7. Halanski MA, Davison JE, Huang JC, Walker CG, Walsh SJ, Crawford HA. Ponseti method compared with surgical treatment of clubfoot: A prospective comparison. J Bone Joint Surg Am. 2010; 92(2):270-278.

8. Lykissas MG, Crawford AH, Eismann EA, Tamai J. Ponseti method compared with soft-tissue release for the management of clubfoot: A meta-analysis study. World J Orthop. 2013; 4(3):144-153.

9. Radler C. The Ponseti method for the treatment of congenital club foot: review of the current literature and treatment recommendations. Int Orthop. 2013; 37(9):1747-1753.

10. Radler C, Mindler GT, Riedl K, Lipkowski C, Kranzl A. Midterm results of the Ponseti method in the treatment of congenital clubfoot. Int Orthop. 2013; 37(9):1827-1831.

11. Zwick EB, Kraus T, Maizen C, Steinwender G, Linhart WE. Comparison of Ponseti versus surgical treatment for idiopathic clubfoot: a short-term preliminary report. Clin Orthop Relat Res. 2009; 467(10):2668-2676.

12. Imhauser G. Follow-up examinations: 30 years of Imhauser clubfoot treatment. Arch Orthop Trauma Surg. 1980; 96(4):259-270.

13. Vanderwilde R, Staheli LT, Chew DE, Malagon V. Measurements on radiographs of the foot in normal infants and children. J Bone Joint Surg Am. 1988; 70(3):407-415.

14. Ayana B, Klungsoyr PJ. Good results after Ponseti treatment for neglected congenital clubfoot in Ethiopia. A prospective study of 22 children (32 feet) from 2 to 10 years of age. Acta Orthop. 2014; 85(6):641-645.

15. Khan SA, Kumar A. Ponseti's manipulation in neglected clubfoot in children more than 7 years of age: a prospective evaluation of 25 feet with long-term follow- up. Journal of Pediatric Orthopaedics-Part B. 2010; 19(5):385-389.

16. Lourenco AF, Morcuende JA. Correction of neglected idiopathic club foot by the Ponseti method. J Bone Joint Surg Br. 2007; 89(3):378-381.

17. Spiegel DA, Shrestha OP, Sitoula P, Rajbhandary T, Bijukachhe B, Banskota AK. Ponseti method for untreated idiopathic clubfeet in Nepalese patients from 1 to 6 years of age. Clin Orthop Relat Res. 2009; 467(5):1164-1170.

18. Chotigavanichaya C, Eamsobhana P, Ariyawatkul T, Saelim C, Kaewpornsawan K. Complications Associated with Ponseti Serial Casting and Surgical Correction via Soft Tissue Release in Congenital Idiopathic Clubfoot. J Med Assoc Thai. 2016; 99(11):1192-1197.

19. Lau JH, Meyer LC, Lau HC. Results of surgical treatment of talipes equinovarus congenita. Clin Orthop Relat Res. 1989; 248:219-226.

20. Yamamoto H, Furuya K. One-stage posteromedial release of congenital clubfoot. J Pediatr Orthop. 1988; 8(5):590-595.

21. Porat S, Kaplan L. Critical analysis of results in club feet treated surgically along the Norris Carroll approach: seven years of experience. J Pediatr Orthop. 1989; 9(2):137-143.

22. Simons GW. Analytical radiography of club feet. J Bone Joint Surg Br. 1977; 59-B(4):485-489.

23. Kaewpornsawan K, Khuntisuk S, Jatunarapit R. Comparison of modified posteromedial release and complete subtalar release in resistant congenital clubfoot: a randomized controlled trial. J Med Assoc Thai. 2007; 90(5):936-941. 